\title{
CLINICA DE LAS NEOPLASIAS MAMARIAS BENIGNAS
}

\section{DR. C. ZuCKERMAN}

Las neoplasias mamarias benignas están constituídas por dos clases de tejidos: epitelail en su mayoría, y conjuntivo; más raramente por tejido adiposo y vascular.

Las epiteliales son derivadas en su mayoría de los acini o de los canales y su constitución parece estar ligada a estas estructuras.

Las conjuntivas nacen en el tejido que rodea a los acini y a los tubulos constituyendo los fibromas de la región.

En algunas ocasiones ambas neoformaciones se combinan apareciendo entonces los fibro-epiteliomas (en su mayoría fibroadenomas); los fibro-adenomas constituyen casi el $80 \%$ de las neo-plasias benignas de la región mamaria. Se pueden encontrar fibro-epiteliomas canaliculares en mucha menor proporción que las neoformaciones antes citadas y pueden ser sólidas o quísticas.

Aspecto clinico. - La parte de la región más frecuentemente ocupada por los adenomas (sólidos o quísticos), es el cuadrante superoextremo. Se encuentran por lo general en personas jóvenes (20-40 años) que presentan tumor único, pequeño, indoloro, de consistencia dura, de límites precisos, móvil, sin ganglios palpables y casi siempre sin secreción serosanguinolenta por el pezón; son raros los casos de adenomas múltiples en un solo lado o bilaterales.

En estas pacientes es esencial practicar examen clínico completo de palpación (anteroposterior), punción, transiluminación y radiografía (Leborgne) y por último el examen histopatológico de la pieza para descartar una cancerización. Es importante señalar la existencia de tumores llamados filoides que son neoplasias mixtas fibro-epiteliales con existencia de tejido mixoide y aspecto foliáceo al corte. 
Los tumores intracanaliculares se observan como los fibroadenomas en un $90 \%$ en mujeres jóvenes, con presencia de telorragia serohemorrágica o serosa y tumoración única cerca al pezón; se trata casi siempre de un papiloma situado en la porción de ensanchamiento del conducto mamario principal. Este puede ser único o múltiple llegando a constituir un tumor llamado dendrítico benigno que puede dar origen a cancerización.

Conducta.- En los fibroadenomas y neoplasias similares 10 preconizado es realizar la extirpación tumoral total; cuando la tumoración es del cuadrante inferior se puede utilizar la insición submamaria; la extirpación tumoral y peritumoral es lo empleado de costumbre y rara vez se acude a la mastectomía simple. En la cirugia de los tumores intracanaliculares se utiliza la insición circular areolar o la radiada descrita por Lecene y Galtier.

\section{OBSERVACIONES}

En diez años (1943-52) se observaron 151 casos de neoplasias mamarias benignas distribuídas así: 73 fibro-adenomas sólidos y 26 quísticos; 16 adenomas sólidos, 7 papilomas intracaniculares, 6 adenomas quísticos, 6 fibroepiteliomas canaliculares quísticos y 5 sólidos, 3 quistes con tejido vegetante intra cavidad, 3 tumores dentríticos intracanaliculares, 3 fibromas puros, 2 lipomas y 1 tumor filoide benigno.

De acuerdo con lo observado, las lesiones tumorales de la mama son más frecuentes con las cancerosas, seguidas de las correspondientes a la mastisis (displasia mamaria, mastopatía endocrina), las neoplasias benignas y por último las correspondientes a granulomas, mastitis, y alteraciones similares. Hay que reconocer que tanto clínica como histológicamente es a veces difícil diferenciar algunos casos de mastosis tumoral de las verdaderas neoplasias benignas; también se debe reconocer la causa hormonal de las mastopatías y la influencia de ella en las neoplasias benignas de la mama, ya que es evidente la existencia de casos mixtos de mastopatías y neoformaciones benignas de ella. 